\title{
Fetal plasma testosterone correlates positively with cortisol
}

\author{
R Gitau, D Adams, N M Fisk, V Glover
}

Arch Dis Child Fetal Neonatal Ed 2005;90:F166-F169. doi: 10.1136/adc. 2004.049320

See end of article for authors' affiliations

Correspondence to:

Correspondence to:
Prof. V Glover, Wolfson and Weston Research Centre for Family Health, Institute of Reproductive and Developmental Biology, Imperial College London, Du Cane Road, London W12 ONN, UK; v.glover@imperial.ac.uk

Accepted 21 May 2004
Background: Fetal exposure to testosterone has been implicated in programming childhood behaviour, but little is known about the determinants of fetal testosterone concentrations.

Aims: To investigate the relation between fetal testosterone and maternal and fetal cortisol.

Methods: Clinically indicated blood samples taken from 44 human fetuses (mean gestational age 27 weeks, range 15-38), together with paired maternal samples, were analysed for testosterone and cortisol concentrations.

Results: Male fetuses had significantly higher concentrations of testosterone than females. Female but not male fetal concentrations rose significantly with gestational age. Fetal testosterone correlated positively with both fetal cortisol and maternal testosterone concentrations. Multiple regression showed that maternal testosterone and fetal cortisol were independently correlated with fetal plasma testosterone in both sexes. Conclusion: Unlike the norm in the adult, where testosterone production is often inhibited by cortisol, in the fetus there is a positive link between the two.
$\mathrm{T}$ he level of fetal exposure to testosterone in utero may be important for programming later behaviour. Animal models have shown that fetal testosterone acts in a dose dependent manner to programme the male fetal brain for its masculine role. ${ }^{1}$ In mice, genital development and later behaviour depend on intrauterine position in the litter, suggestive of a testosterone effect. ${ }^{2}$ In humans, girls with congenital adrenal hyperplasia, which results in a deficiency of cortisol but an excess of testosterone, show some masculinisation, including a greater tendency to "rough and tumble" play and selection of masculine toys. ${ }^{3}$ They also have altered laterality. ${ }^{4}$ Grimshaw and colleagues ${ }^{5}$ showed that amniotic fluid testosterone concentrations correlated with some aspects of spatial ability in girls, but not in boys. It has also been suggested that certain neurodevelopmental disorders that are more common in males such as dyslexia and autism, result in part from excessive exposure to testosterone in utero. ${ }^{67}$ Eye contact at 1 year, and language development at 18 months and 2 years (reduced development of which are indices of autistic spectrum behaviour) have been found to correlate with the amniotic fluid testosterone concentrations. $^{89}$

Prenatal stress has been shown in rodent models to have an effect on sex typical behaviour of the offspring. ${ }^{10}$ Ward has shown that stressing the pregnant dam reduced the crucial testosterone surge at days 18-19 in male fetuses and also resulted in feminisation of adult sexual behaviour in male offspring. ${ }^{11}$ However, prenatal stress also results in reduced maternal behaviour in female offspring. ${ }^{12}$ In humans, maternal anxiety in pregnancy is linked with an increased likelihood of behavioural problems in childhood, including hyperactivity/attention deficit in boys. ${ }^{13}$ It is also linked with an increased incidence of mixed handedness in the child..$^{14}{ }^{15}$ As altered laterality (left and mixed handedness) is more common in boys than girls, and is also increased in congenital adrenal hyperplasia, ${ }^{4}$ it might be related to an increased level of exposure to testosterone.

In adult humans there is evidence that cortisol production and testosterone are inversely related, and that stress can suppress testosterone production. ${ }^{16}{ }^{17}$ We have previously reported a linear correlation between maternal and fetal cortisol concentrations. ${ }^{18}{ }^{19}$ If fetal cortisol and testosterone were inversely related, as in the adult, this would make any masculinisation of the fetus secondary to maternal prenatal stress hard to explain. One would expect the reverse, a feminising effect.

It is therefore of interest to understand the relation between the function of the hypothalamic-pituitary-adrenal (HPA) axis and testosterone production in the fetus. In this study we investigated the correlates of fetal plasma testosterone with the primary aim of characterising the relation between fetal testosterone and cortisol concentrations. Fetal blood samples were taken at clinically indicated fetal blood sampling. When possible, maternal blood samples were taken at the same time for comparison. Although previous studies have examined testosterone concentrations in fetal blood ${ }^{20}$ and amniotic fluid, ${ }^{21}{ }^{22}$ none have examined the relation between testosterone and cortisol in the fetus.

\section{METHODS}

\section{Experimental subjects}

Forty four women with pregnancies undergoing clinically indicated fetal blood sampling, and/or intrauterine blood/ platelet transfusion at the Centre for Fetal Care, Queen Charlotte's and Chelsea Hospital, London, UK were recruited (mean gestational age 27 weeks, range 15-38). Twenty eight fetuses were normal; six had an anomalous karyotype (triosomy $18, \mathrm{n}=3$; triosomy $2 \mathrm{l}, \mathrm{n}=3$ ) and 10 had some non-hydropic structural anomaly (abnormal heart, $\mathrm{n}=5$; anencephaly, $\mathrm{n}=1$; brain tumour, $\mathrm{n}=1$; ectrodactyly, $\mathrm{n}=1$; IUGR, $n=2$ ). Cortisol results from some of these fetuses have been reported previously. ${ }^{19}$ If samples were obtained from an individual fetus on more than one occasion, only the first was used. The sex of the fetus was known for 40 of these subjects.

The indications for fetal blood sampling were rapid karyotyping $(n=20)$ or suspected anaemia $(n=1)$, and for intrauterine transfusion, were fetal anaemia $(n=19)$ or thrombocytopenia $(\mathrm{n}=4)$ in alloimmunised pregnancies. Eleven blood samples were collected at the placental cord insertion (PCI) and 33 at the intrahepatic vein (IHV). All baseline samples were collected prior to transfusion and within 10 minutes of needle entry, within which fetal cortisol concentrations are known not to rise. ${ }^{20}$ Neither fetal neuromuscular blockade nor analgesia was used. Mothers did not receive sedation. The purity of fetal samples was confirmed by comparison of fetal and maternal 
mean corpuscular volumes and subsequent Kleihauer-Betke testing.

Ethical approval for the study was granted by the Hammersmith Hospitals Trust ethics committee, and written informed consent was obtained from all the mothers for the collection of additional blood samples for research purposes.

\section{Blood samples}

Following collection of clinical samples, up to $1-2 \mathrm{ml}$ additional venous fetal blood was drawn into a syringe and placed in a chilled heparinised tube. Maternal blood $(7 \mathrm{ml})$ was collected, when possible, by venepuncture into a heparinised Vacutainer (Becton Dickinson, Meylan Cedex, France) immediately before transabdominal needle insertion.

Blood samples were spun in a refrigerated centrifuge at $3000 \mathrm{~g}$ for 15 minutes at $4^{\circ} \mathrm{C}$, to separate plasma, which was collected over ice and stored in aliquots at $-80^{\circ} \mathrm{C}$ until subsequent batch assay.

\section{Assays}

Total plasma testosterone was assayed using a direct plasma radioimmunoassay (RIA) (DPC, Los Angeles, USA). The lower limit of sensitivity was $0.14 \mathrm{nmol} / \mathrm{l}$, and the assay coefficient of variation $10.5 \%$. Total cortisol concentrations were assayed using a standard solid phase RIA (DPC, Los Angeles, USA). The lower limit of sensitivity was $10 \mathrm{nmol} / \mathrm{l}$ and the assay coefficient of variation $5.3 \%$. Maternal and fetal plasma sample pairs were analysed in the same assay run.

\section{Statistics}

Normally distributed data were analysed by standard parametric statistics using SPSS 10.0 for Windows (Chicago, IL), using paired or unpaired $t$ tests or Pearson correlations as appropriate. Baseline fetal cortisol and testosterone and maternal testosterone and cortisol concentrations were all first normalised by $\ln$ transformation before any statistical analysis. The response to transfusion was analysed using $\Delta$ (post-transfusion stress hormone concentration - pretransfusion stress hormone concentration) values. Probability values are based on two tailed analysis unless stated otherwise.

\section{RESULTS}

Table 1 shows the plasma hormone concentrations for the whole sample. An initial univariate analysis showed that fetal plasma testosterone did not correlate with $\mathrm{pH}, \mathrm{pCO}_{2}$, or $\mathrm{pO}_{2}$. There was no difference in these parameters, or in fetal testosterone or fetal cortisol whether the fetus was normal or anomalous (all by two tailed Student's $t$ test). The results from normal and anomalous fetuses were therefore combined for further analyses.

\begin{tabular}{|c|c|c|c|}
\hline & $n$ & $\begin{array}{l}\text { Geometric } \\
\text { mean }\end{array}$ & $\begin{array}{l}\text { Interquartile } \\
\text { range }\end{array}$ \\
\hline Gestational age & 44 & 27 & $23.5-32$ \\
\hline Fetal testosterone $(\mathrm{nmol} / \mathrm{l})$ & 44 & 1.4 & $0.75-2.5$ \\
\hline Males & 23 & 2.1 & $1.7-2.9$ \\
\hline Females & 17 & 0.78 & $0.45-1.3$ \\
\hline Fetal cortisol (nmol/l) & 41 & 57 & $7-350$ \\
\hline Males & 22 & 57 & $7-350$ \\
\hline Females & 17 & 53 & $9-189$ \\
\hline Maternal testosterone $(\mathrm{nmol} / \mathrm{l})$ & 34 & 1.7 & $0.95-2.7$ \\
\hline Maternal cortisol (nmol/l) & 32 & 644 & $499-950$ \\
\hline
\end{tabular}

Male fetuses had significantly higher testosterone concentrations than females $\mathrm{p}<0.001$ ) (fig 1 ). The gestational age range was similar in the two sexes: males, geometric mean 27 weeks, range 17-38 weeks; females, geometric mean 27 weeks, range, 20-36 weeks. Testosterone increased significantly in females with gestational age $(r=0.63, \mathrm{p}<0.01)$ but not in the males. Fetal cortisol was not significantly related to gestational age in either the males or females. With maternal cortisol and maternal testosterone, there was no significant relation with gestational age or difference with fetal sex.

There was no acute change in testosterone concentration after transfusion through either the IHV (mean pre- and post-transfusion, both $1.8 \mathrm{nmol} / \mathrm{l}, \mathrm{n}=14$ ) or through the PCI (mean pre-transfusion $1.8 \mathrm{nmol} / \mathrm{l}$, mean post-transfusion $1.7 \mathrm{nmol} / \mathrm{l}, \mathrm{n}=9$ ). This was also found after a regression analysis adjusting for baseline fetal testosterone.

Table 2 shows the correlations between testosterone and cortisol in both fetus and mother.

The correlation between cortisol and testosterone in fetal plasma was positive $(r=0.407, \mathrm{p}=0.008)$. In contrast, maternal testosterone was not significantly correlated with maternal cortisol -0.032 . Fetal plasma testosterone correlated positively with maternal concentrations $(r=0.414, \mathrm{p}=0.015)$ and maternal and fetal cortisol were also positively correlated $(r=0.526, \mathrm{p}=0.002)$. Similar patterns were observed for the male and female subgroups (all correlations greater than $0.4)$, but due to the smaller numbers not all were significant.

Multiple regression analysis was next used and showed that fetal sex, fetal cortisol, and maternal testosterone were all significantly and independently related to fetal plasma testosterone concentrations. In this analysis there was no contribution from maternal cortisol (table 3 ).

\section{DISCUSSION}

The main finding of this study is that, unlike the norm in the adult, there was a positive correlation between fetal cortisol and testosterone concentrations. Thus the mechanism of inter-related control of the HPA axis and testosterone production is different in the fetus compared with the adult.

As expected, we found that testosterone concentrations are higher in the male than the female fetus, although the differences were not large. This confirms previous results in amniotic fluid ${ }^{21}{ }^{22}$ and cord blood. ${ }^{20}$ We also found that there was a positive relation with gestational age in female but not male fetuses. This also confirms previous findings. BeckPeccoz and colleagues ${ }^{20}$ have reported, as we show here (fig 1), that by term, concentrations are similar in the two

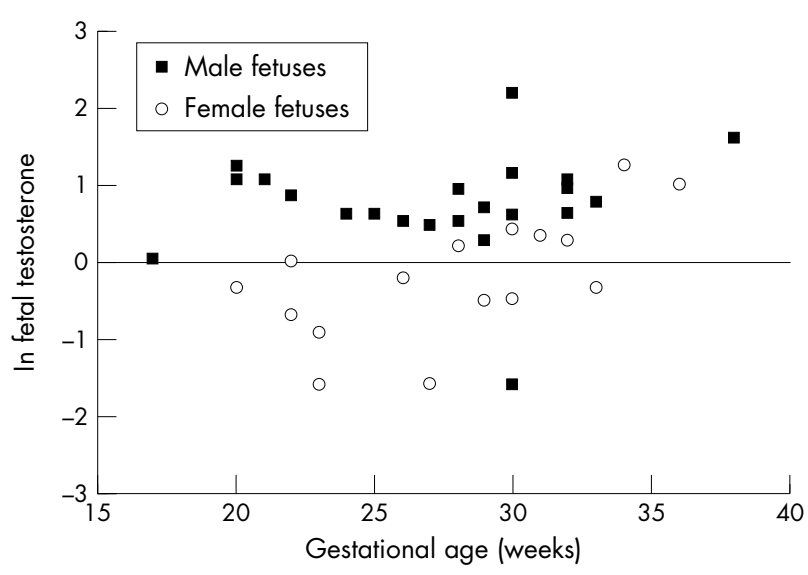

Figure 1 Ln testosterone concentrations $(\mathrm{nmol} / \mathrm{l})$ and gestational age in male fetuses (NS) and female fetuses $(r=0.63, p<0.01)$. 
Table 2 Pearson correlations between maternal and fetal cortisol and testosterone concentrations (all analyses were carried out with the In transformed values)

\begin{tabular}{llll}
\hline & $\begin{array}{l}\text { Fetal } \\
\text { cortisol }\end{array}$ & $\begin{array}{l}\text { Maternal } \\
\text { testosterone }\end{array}$ & $\begin{array}{l}\text { Maternal } \\
\text { cortisol }\end{array}$ \\
\hline Fetal testosterone & 0.407 & 0.414 & 0.416 \\
& $(0.008)$ & $(0.015)$ & $(0.018)$ \\
Fetal testosterone & 0.530 & 0.618 & 0.462 \\
(males) & $(0.011)$ & $(0.005)$ & $(0.052)$ \\
Fetal testosterone & 0.44 & 0.443 & 0.641 \\
(females) & $(0.078)$ & $(0.150)$ & $(0.018)$ \\
Fetal cortisol & - & 0.123 & 0.526 \\
& & $(0.511)$ & $(0.002)$ \\
Maternal testosterone & - & - & -0.032 \\
& & & $(0.866)$ \\
\hline
\end{tabular}

sexes, although they measured free rather than total testosterone. However the large majority of our sample (only one below 20 weeks) were in the second half of gestation, and there may be a surge of testosterone earlier than this in the males.

The positive correlation between cortisol and testosterone may be because fetal testosterone is produced partially in the adrenal, and like cortisol is, at least in part, under control of ACTH. ${ }^{23}$ In addition, Smith and colleagues ${ }^{24}$ have shown that placental corticotrophin releasing hormone $(\mathrm{CRH})$ promotes fetal adrenal secretion of DHEA-S, and have identified CRH receptors in fetal adrenal tissue. ${ }^{25}$ It is thus also possible that placental CRH induces fetal DHEA-S and this in turn is a precursor for testosterone. With the limited volume of the fetal blood samples, we were strictly limited in what we could study, and were not able to measure DHEA-S directly. It would also be of interest to measure the concentrations of the steroid binding proteins, which affect the amount of free steroid available. Fetal cortisone would also be relevant, as a possible index of maternal cortisol crossing the placenta and metabolised by $11 \quad \beta$-hydroxysteroid dehydrogenase (11 $\beta$-HSD 2). More research is clearly needed to disentangle the pathways involved.

Cortisol and testosterone in the fetus are clearly not under identical control; there are likely to be several different determinants of fetal testosterone concentrations. Whereas there was an increase in testosterone with gestational age in females, there was no such increase in cortisol over this age range. Also, unlike the case in our previous studies with cortisol, ${ }^{1926}$ we found no acute increase in testosterone after transfusions that involved piercing the fetal abdomen at the IHV. If there is some joint control by ACTH it must have a different time course.

The positive correlation shown here between maternal and fetal testosterone concentrations is similar to that which we have previously found with cortisol. ${ }^{18}{ }^{19}$ Both are liposoluble steroids that would be expected to cross the placenta readily. This is different from the case with $\beta$-endorphin or noradrenaline, which are not lipophilic and for which we have found no correlation between mother and fetus. ${ }^{19} 27$ With cortisol, maternal plasma concentrations are about 11 fold higher than fetal concentrations; with testosterone the concentrations found here in the two compartments were similar. This may reflect active metabolism of cortisol in the placenta by $11 \beta$-HSD $2 .{ }^{28}$ However, a correlation does not prove a mechanism; and although the links between maternal and fetal testosterone suggest passage across the placenta, it is also possible that both are under joint or similar control.

Fetal blood sampling procedures are becoming less frequent, ${ }^{29}$ and so in this study, unlike our previous ones, ${ }^{19} 27$
Table 3 Multiple regression analysis for fetal testosterone $(\ln )$ as dependent variable

\begin{tabular}{lrll}
\hline & beta & $\boldsymbol{t}$ & $\mathbf{p}$ \\
\hline Fetal cortisol (In) & 0.54 & 5.8 & $<0.001$ \\
Maternal testosterone (In) & 0.39 & 4.2 & $<0.001$ \\
Sex & -0.50 & 5.4 & $<0.001$ \\
\hline
\end{tabular}

we necessarily needed to include samples from non-normal fetuses. Six of the group had an anomalous karyotype and 10 had some non-hydropic structural anomaly. However this made no difference to any of the parameters studied here. When we studied the normal fetuses alone, similar, although non-significant correlations emerged. We have also found a similar significant positive correlation between cortisol and testosterone concentrations in amniotic fluid in a large sample from normal fetuses (unpublished observations).

Although the testosterone did not show an acute rise in response to stress, the positive correlation between fetal cortisol and testosterone concentrations suggests that some of the factors that cause raised fetal cortisol concentration may also cause an increase in testosterone concentration. This in turn may influence fetal development in ways associated with a more masculine profile.

\section{Authors' affiliations}

R Gitau, D Adams, N M Fisk, V Glover, Wolfson and Weston Research Centre for Family Health, Institute of Reproductive and Developmental Biology, Imperial College London, Du Cane Road, London W12 ONN, UK

Financial support: We acknowledge support from the Henry Smith Charity and the Institute of Obstetrics and Gynaecology Trust, and equipment support from the John Ellerman Foundation and the Children Nationwide Medical Research Foundation

Competing interests: none declared

\section{REFERENCES}

1 Goy RW, McEwen BS. Sexual differentiation of the brain. Cambridge, MA: MIT Press, 1980.

2 Vandenbergh JG, Huggett $\mathrm{Cl}$. The anogenital distance index, a predictor of the intrauterine position effects on reproduction in female house mice. Lab Anim Sci 1995;45:567-73.

3 Berenbaum SA, Hines M. Early androgens are related to childhood sex-typed toy preferences. Psychol Sci 1992;3:203-6.

4 Nass R, Baker S, Speiser P, et al. Hormones and handedness: left hand bias in female congenital hyperplasia patients. Neurology 1987;37:711-15.

5 Grimshaw G, Sitarenios G, Finegan J. Mental rotation at 7 years: relations with prenatal testosterone and spatial play experiences. Brain Cogn 1995;29:85-100.

6 Geschwind N, Galaburda A. Cerebral lateralisation. Cambridge, MA: MIT Press, 1987.

7 Baron-Cohen S, Hammer J. Is autism an extreme form of the "male brain"? Adv Inf Res 1997;11:193-217.

8 Lutchmaya S, Baron-Cohen S, Raggatt P. Foetal testosterone and vocabulary size in 18- and 24-month-old infants. Inf Behav Dev 2002;24:418-24.

9 Lutchmaya S, Baron-Cohen S, Raggatt P. Foetal testosterone and eye contact in 12 month old human infants. Inf Behav Dev 2002;25:327-35.

10 Weinstock M. Alterations induced by gestational stress in brain morphology and behaviour of the offspring. Prog Neurobiol $2001 ; 65: 427-51$.

11 Ward II. The prenatal stress syndrome: current status. Psychoneuroendocrinology 1984;9:3-11.

12 Kinsley $\mathrm{CH}$, Bridges RS. Prenatal stress and maternal behaviour in intact virgin rats: response latencies are decreased in males and increased in females. Horm Behav 1988;22:76-89.

13 O'Connor TG, Heron J, Golding J, et al. Maternal antenatal anxiety and behavioural problems in early childhood. Br J Psychiatry 2002;180:502-8.

14 Obel C, Hedegaard M, Henriksen TB, et al. Psychological factors in pregnancy and mixed-handedness in the offspring. Dev Med Child Neurol 2003;45:557-61

15 Glover V, O'Connor T G, Heron J, et al. Antenatal maternal anxiety is linked with atypical handedness in the child. Early Hum Dev 2004;79:107-18. 
16 Cumming DC, Quigley ME, Yen SS. Acute suppression of circulating testosterone levels by cortisol in men. J Clin Endocrinol Metab 1983;57:671-3

17 Chatterton RT, Dooley SL. Reversal of diurnal cortisol rhythm and suppression of plasma testosterone in obstetric residents on call. J Soc Gynecol Invest 1999;6:50-4

18 Gitau R, Cameron A, Fisk NM, et al. Fetal exposure to maternal cortisol. Lancet 1998;352:707-8.

19 Gitau R, Fisk NM, Cameron A, et al. Fetal HPA stress responses to invasive procedures are independent of maternal responses. J Clin Endocrinol Metab 2001;86:104-9

20 Beck-Peccoz P, Padmanabhan V, Baggianai AM, et al. Maturation of hypothalamic-pituitary-gonadal function in normal human fetuses. J Clin Endocrinol Metab 1991;73:525-32.

21 Rodeck CH, Gill D, Rosenberg DA, et al. Testosterone levels in midtrimester maternal and fetal plasma and amniotic fluid. Prenat Diagn 1985;5:175-81.

22 Finegan JK, Bartleman B, Wong PY. A window for the study of prenatal sex hormone influences on postnatal development. J Genet Psychol 1989;150:101-12.
23 Fujieda K, Faiman C, Reyes Fl, et al. The control of steroidogenesis by human fetal adrenal cells in tissue culture. 1. Response to adrenocorticotropin. J Clin Endocrinol Metab 1981;53:34-8.

24 Smith R, Mesanio S, Chan E-C, et al. Corticotropin-releasing hormone directly and preferentially stimulates dehydroepiandrosterone sulfate secretion by human fetal adrenal cortical cells. J Clin Endocrinol Metab 1998;83:2916-20.

25 Karteris E, Randeva HS, Grammatopoulos DK, et al. Expression and coupling characteristics of the $\mathrm{CRH}$ and orexin type 2 receptors in human fetal adrenals. J Clin Endocrinol Metab 2001;86:4512-19.

26 Giannakoulopoulos X, Sepulveda W, Kourtis P, et al. Fetal plasma cortisol and $\beta$-endorphin response to intrauterine needling. Lancet 1994;344:77-81.

27 Giannakoulopoulos $\mathbf{X}$, Teixeira J, Fisk N, et al. Human fetal and maternal noradrenaline responses to invasive procedures. Pediatr Res 1999:45:494-9.

28 O'Regan D, Welberg LAM, Holmes MC, et al. Glucocorticoid programming of pituitary-adrenal function: mechanisms and physiological consequences. Semin Neonatal 2001:6:319-29.

29 Fisk NM, Bower S. Fetal blood sampling in retreat. BMJ 1993;307:620.

\section{IMAGES IN NEONATAL MEDICINE}

\section{Cutis marmorata telangiectatica congenita}

A baby boy born to non-consanguineous parents showed skin lesions of generalised persistent cutis marmorata, dilated superficial veins, and telangiectasia involving the limbs, trunk, and scalp (fig 1). The lesions spared the palms and soles, and systemic examination was normal. An ultrasonogram of the head and abdomen and echocardiogram of the heart were normal.

Cutis marmorata telangiectatica congenita $^{1}$ is a rare benign sporadic congenital vascular anomaly characterised by persistent cutis marmorata, telangiectasia, and phlebectasia and often associated with skin atrophy and ulceration. ${ }^{2}$ The cutaneous lesions commonly occur on the legs, arms, and trunk and rarely involve the face and scalp. Associated abnormalities such as body asymmetry, vascular and neurological anomalies, glaucoma, macrocephaly, and psychomotor retardation occur in many patients. The diagnosis is mainly clinical, and prognosis is generally good, with cutaneous lesions improving during infancy. There is no specific treatment, and long term follow up is indicated with associated abnormalities.

P Manikoth, P A K Nair, M G Pai, M A A Ajmi Special Care Baby Unit, Royal Hospital, Muscat, Oman; manikoth@omantel.net.om

Constent for figure 1 was obtained from the patient's parents.

\section{REFERENCES}

1 van $L, C$. HJ. Ueber eine seltene angeborene Haut-anomalie (Cutis marmorata telangiectatica congenita). Acta Derm Venereol 1922;3:202-11

2 Amitai DB, Fichman S, Merlob P, et al. Cutis marmorata telangiectatica congenita: clinical findings in 85 patients. Pediatr Dermatol 2000;17:100-4.

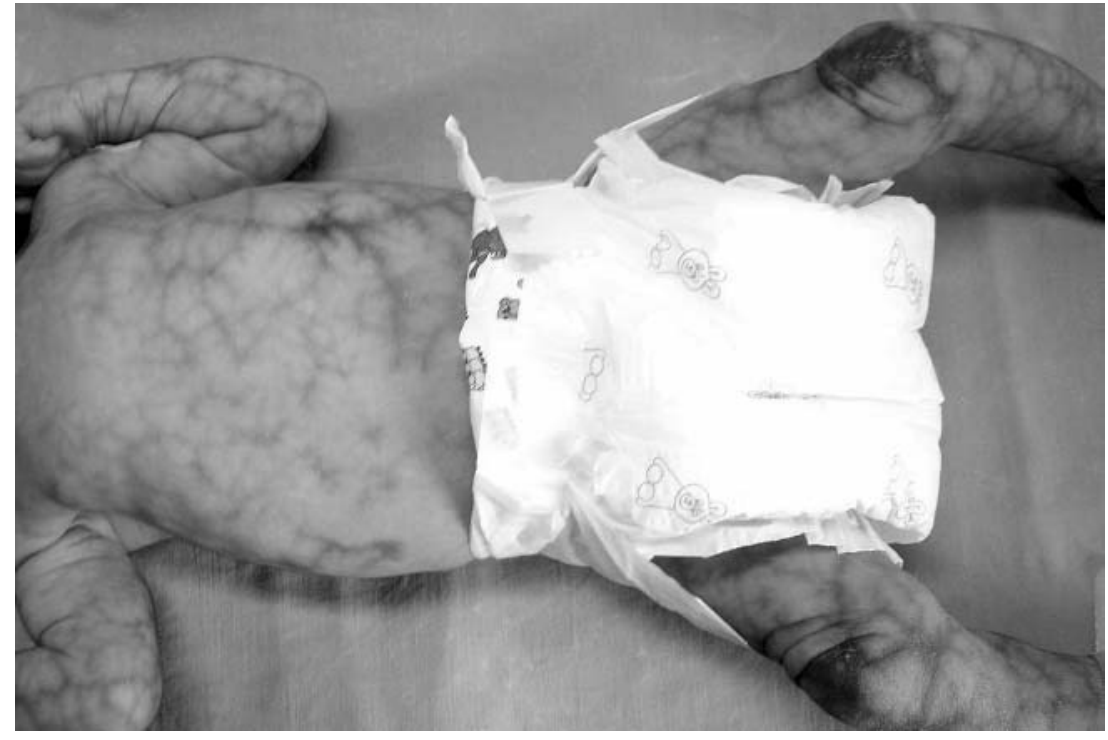

Figure 1 Photograph showing generalised cutis marmorata, dilated superficial veins, and telangiectasia involving the trunk and limbs. Consent for this figure was obtained from the patient's parents. 